\begin{tabular}{|c|c|c|}
\hline Case Reports in & \multicolumn{2}{|c|}{ Case Rep Gastroenterol 2014;8:77-81 } \\
\hline Gastroenterology & $\begin{array}{l}\text { DOI: 10.1159/000360845 } \\
\text { Published onlıne: March 13, } 2014\end{array}$ & $\begin{array}{l}\text { ( ) } 2014 \text { S. Karger AG, Basel } \\
1662-0631 / 14 / 0081-0077 \$ 39.50 / 0 \\
\text { www.karger.com/crg }\end{array}$ \\
\hline & \multicolumn{2}{|c|}{$\begin{array}{l}\text { This is an Open Access article licensed under the terms of the Creative Common } \\
\text { Attribution-NonCommercial } 3.0 \text { Unported license (CC BY-NC) (www.karger.com/OA } \\
\text { license), applicable to the online version of the article only. Distribution permitted for non } \\
\text { commercial purposes only. }\end{array}$} \\
\hline
\end{tabular}

\title{
Gastric Metastasis of Lung Cancer Mimicking an Adrenal Tumor
}

\author{
Tsung I Hung $^{a} \quad K^{\prime}$ uang-En Chu ${ }^{b}$ Yenn Hwei Chou ${ }^{a} \quad$ Kuo-Ching Yang ${ }^{b}$ \\ ${ }^{a}$ Department of General Surgery and ${ }^{b}$ Division of Hepatology and Gastroenterology, \\ Department of Internal Medicine, Shin Kong Wu Ho-Su Memorial Hospital, Taipei, Taiwan
}

\section{Key Words}

Lung cancer · Gastric metastasis · Retroperitoneal tumor

\begin{abstract}
Lung cancer is one of the leading causes of cancer deaths worldwide. Metastatic spreads of lung cancer are often found in the adrenal glands, bone, liver, brain and kidneys; the gastrointestinal tract is less commonly involved. However, according to some reports in the literature, the incidence of gastrointestinal metastases, most of them asymptomatic, might be as frequent as $11 \%$ in autopsy studies of lung cancer, which suggests that this condition is not as rare as it was previously considered. We report a very rare case of small cell lung cancer with a solitary gastric metastasis mimicking an adrenal tumor which was belatedly diagnosed due to its unusual presentation and treated actively with surgery and chemotherapy, achieving a relatively favorable outcome.

(c) 2014 S. Karger AG, Basel
\end{abstract}

\section{Introduction}

Primary lung cancers rarely metastasize to the gastrointestinal tract and frequently present disseminated spreads at the time of the diagnosis [1]. Although the incidence of metastasis to the gastrointestinal tract has been reported to be as high as $11 \%$ in autopsy studies according to some reports, solitary metastasis to the stomach from lung cancer is exceptionally rare. We herein report an interesting case of lung cancer with a solitary gastric metastasis which penetrated into the retroperitoneum and mimicked a small adrenal tumor.

The patient described in this report was under regular follow-up for small cell carcinoma of the lung. A small tumor was found in the left adrenal area while he was stable and free of symptoms 4 years after the lung cancer had been diagnosed and treated with chemotherapy. This lesion was initially interpreted as an insignificant adrenal incidentaloma and left 
Hung et al.: Gastric Metastasis of Lung Cancer Mimicking an Adrenal Tumor

untreated until its rapid growth was noticed in a subsequent computed tomography checkup performed 6 months later. The patient was treated surgically firstly under the impression of lung cancer with solitary metastasis to the left adrenal gland; however, during surgery this rapidly enlarging tumor was unexpectedly found to originate from the gastric wall and not to be related to the adrenal gland. The tumor was resected. The patient tolerated postoperative chemotherapy well and had an acceptable general performance during the year after the surgery until metastatic liver tumors were found during a routine follow-up. He received further chemotherapy, and although the treatment course was complicated by several episodes of pancytopenia, he recovered and is still doing relatively well, currently following regular visits to the outpatient clinic. In the past, a patient with lung cancer and gastrointestinal metastasis might have been treated with merely chemotherapy due to poor prognosis; however, according to the experience observed in our patient and two case reports, an active management of the metastasis, such as surgical intervention along with chemotherapy, might still prolong the patient's survival significantly in selective cases of lung cancer.

\section{Case Report}

A 47-year-old man with a long-term heavy smoking history presented to the emergency room with an one-month history of progressive dyspnea on exertion, productive cough, marked weight loss, profuse diaphoresis at night, neck swelling and dysphagia in early October 2008. A chest film revealed a large soft tissue density in the right upper lobe of the lung and remarkable widening of the upper mediastinum. A subsequent chest computed tomography disclosed a large space-occupying lesion in the right upper lobe of the lung encasing the superior vena cava and the right pulmonary artery (fig. 1). Bronchoscopic examination revealed a picture consistent with external compression in the right trachea where the mucosa presented irregularities, narrowing of the orifice of the right upper lobe with suspicious tumor tissue. The pathological report of the tissue biopsy proved it to be small cell carcinoma of the lung. The patient was hospitalized and received radiotherapy to relieve the superior vena cava syndrome, and prophylactic whole brain radiation was undertaken as well. He favorably tolerated six successive courses of chemotherapy with VP-16 and cisplatin later on and had regular follow-ups in the outpatient clinic with a quite satisfactory general performance and relatively good control of the primary lung lesion in the following 4 years.

In November 2011, a follow-up chest computed tomography disclosed a small, illdefined tumor $(1.8 \times 1.4 \mathrm{~cm})$ in the left adrenal area (fig. 2a). This lesion was initially interpreted as a non-functioning adrenal incidentaloma with no remarkable clinical relevance and was left for observation. However, the patient, who was free of symptoms, underwent a new chest computed tomography follow-up 6 months later (May 2012) and surprisingly a remarkable enlargement of the previously suspected left adrenal tumor was noted $(3.3 \times 2.5 \mathrm{~cm})$ (fig. $2 \mathrm{~b})$. A distant metastasis from the lung cancer to the left adrenal gland was then considered and the patient was hospitalized again for surgical intervention by the urologists. Retroperitoneoscopy was initially performed to localize the suspicious metastatic left adrenal tumor. Unexpectedly, the surgeons found an intact left adrenal gland, and the tumor was actually arising from the posterior wall of the gastric body and penetrating into the retroperitoneal space close to the left kidney through a defect in the posterior peritoneum, mimicking an adrenal tumor. Laparotomy was immediately undertaken instead, and wedge resection of the tumor from the stomach was performed accordingly. The path- 
Hung et al:: Gastric Metastasis of Lung Cancer Mimicking an Adrenal Tumor

ological analysis of the resected tumor revealed identical pictures as the primary lung lesion (immunohistochemical stain positive both for TTF-1 and CD-56) (fig. 3).

After the operation, the patient received further chemotherapy with etoposide and cisplatin and had a relatively good general performance in the meantime. In May 2013, exactly 1 year after the abdominal surgery, a follow-up computed tomography showed several metastatic tumors in the liver and additional chemotherapy with topotecan was instituted. Although the patient underwent an eventful clinical course with several episodes of pancytopenia, the chemotherapy could be finally completed and he currently still has regular follow-ups at the outpatient clinic 15 months after excision of the metastatic tumor in the stomach.

\section{Discussion}

Primary lung cancer is often asymptomatic, and $50 \%$ of patients with lung cancer already have metastases at the first diagnosis [2]. Lung cancer usually metastasizes to the adrenal gland, bone, liver, brain and infrequently to the digestive system [2,3]. Although most of the reports in the reviewed literature point out that patients with gastrointestinal metastases secondary to lung cancer usually have a poor prognosis and do not survive longer than 16 weeks after the diagnosis [4], two case reports made interesting observations on the long-term survival of lung cancer patients with metastasis to the stomach [5, 6]. These particular cases are similar to our patient in the sense that they also had solitary gastric metastasis in the absence of general cancer dissemination when the disease was diagnosed that and the solitary metastasis was resectable surgically. According to these two case reports, if these particular patients had received only chemotherapy, the life expectancy would most probably have been shorter than 6 months [7]. It is hypothesized that metastasis to the stomach, as many metastasis, follows a hematological spread, and in these selective cases active management of the solitary gastric metastasis, instead of palliative treatment such as chemotherapy alone, along with adequate control of the primary lung tumor may yield a more favorable outcome [8]. Autopsy studies report an incidence varying from $0.2 \%$ [8] to as high as $11 \%$ for gastric metastasis [4]. Active and routine screening in search of asymptomatic, early and still resectable gastric metastases is warranted as it might result in longer patient survival.

In our patient, gastric metastasis presenting as a retroperitoneal tumor mimicking an adrenal tumor is merely anecdotal. This very rare presentation was misleading the correct diagnosis, resulting in a delay of treatment, but even so an active management such as surgical resection coupled with chemotherapy was still adopted for this belatedly recognized metastasis and a remarkably favorable outcome was achieved. Finally, based on the experience with our patient, we suggest that asymptomatic solitary gastric metastasis might be latent for a long time and even belatedly identified, but still deserves to be treated actively for possible favorable patient survival.

\section{Disclosure Statement}

No conflicts of interests are declared by the authors. 


\begin{tabular}{l|l}
\hline Case Rep Gastroenterol 2014;8:77-81 \\
\hline DOI: 10.1159/000360845 & $\begin{array}{l}\text { ○ 2014 S. Karger AG, Basel } \\
\text { www.karger.com/crg }\end{array}$ \\
\hline
\end{tabular}

Hung et al.: Gastric Metastasis of Lung Cancer Mimicking an Adrenal Tumor

\section{References}

1 Kadakia SC, Parker A, Canales L: Metastatic tumors to the upper gastrointestinal tract: endoscopic experience. Am J Gastroenterol 1992;87:1418-1423.

2 Sternberg A, Giler S, Segal I, Shmuter Z, Kott I: Small bowel perforation as the presenting symptom of squamous cell carcinoma of the lung. Clin Oncol 1980;6:181-186.

-3 Steinhart AH, Cohen LB, Hegele R, Saibil FG: Upper gastrointestinal bleeding due to superior mesenteric artery to duodenum fistula: rare complication of metastatic lung carcinoma. Am J Gastroenterol 1991;86: 771-774.

4 McNeill PM, Wagman LD, Neifeld JP: Small bowel metastases from primary carcinoma of the lung. Cancer 1987;59:1486-1489.

5 Aokage K, Yoshida J, Ishii G, Takahashi S, Sugito M, Nishimura M, Ochiai A, Nagai K: Long-term survival in two cases of resected gastric metastasis of pulmonary pleomorphic carcinoma. J Thorac Oncol 2008;3:796799.

6 Jansen JM, Oldenburg B, van Milligen de Wit AW: Small intestinal metastasis from non-small-cell carcinoma of the lung: a rare cause of GI bleeding of obscure origin. Gastrointest Endosc 2004;59:447-449.

7 Koch B, Tannapfel A, Vieth M, Grün R: Gastric metastasis from small cell lung cancer. Pneumologie 2009;63: 585-587.

8 Sileri P, D’Ugo S, Del Vecchio Blanco G, Lolli E, Franceschilli L, Formica V, Anemona L, De Luca C, Gaspari AL: Solitary metachronous gastric metastasis from pulmonary adenocarcinoma: report of a case. Int J Surg Case Rep 2012;3:385-388.
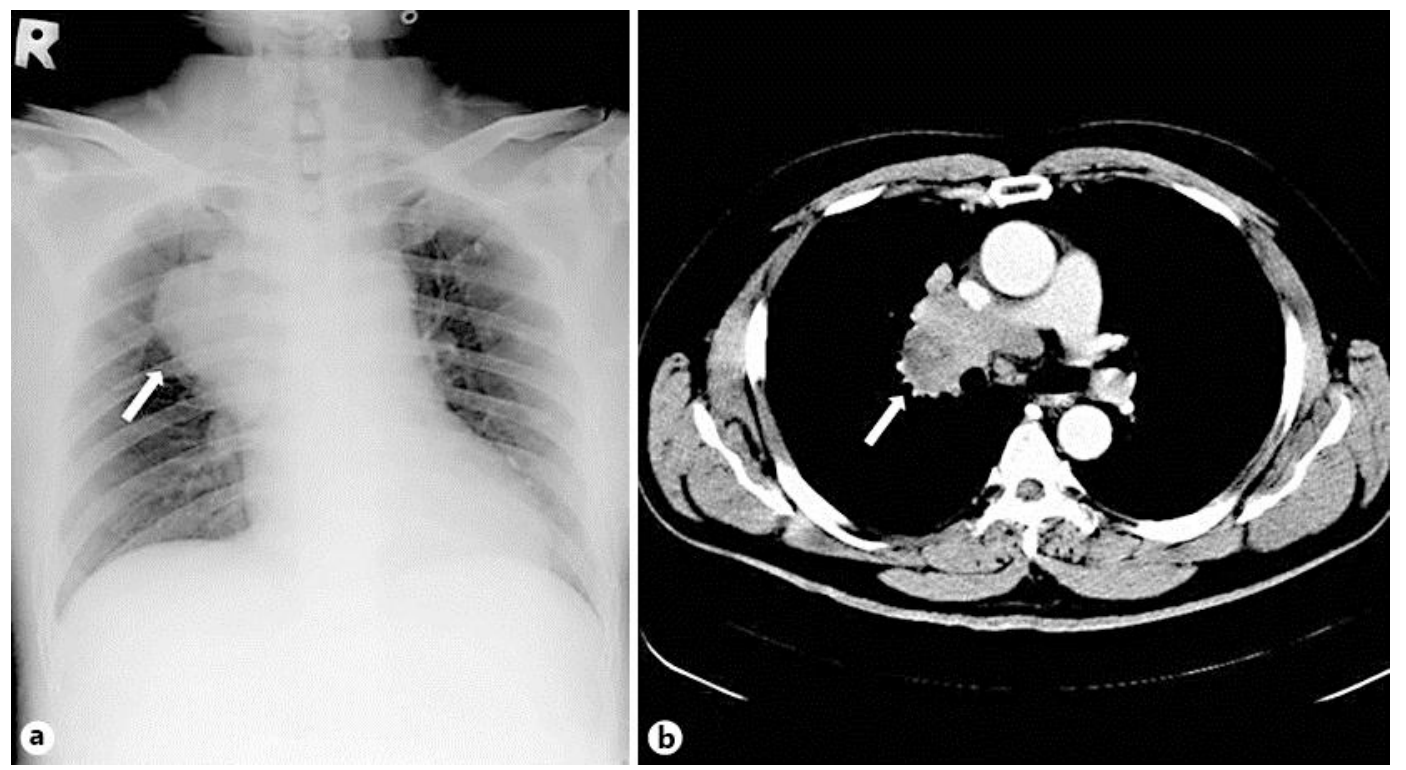

Fig. 1. a A chest film revealed a large soft tissue density in the right upper lobe of the lung. b A subsequent chest computed tomography disclosed a large space-occupying lesion in the right upper lobe of the lung encasing the superior vena cava and the right pulmonary artery. 
Hung et al.: Gastric Metastasis of Lung Cancer Mimicking an Adrenal Tumor
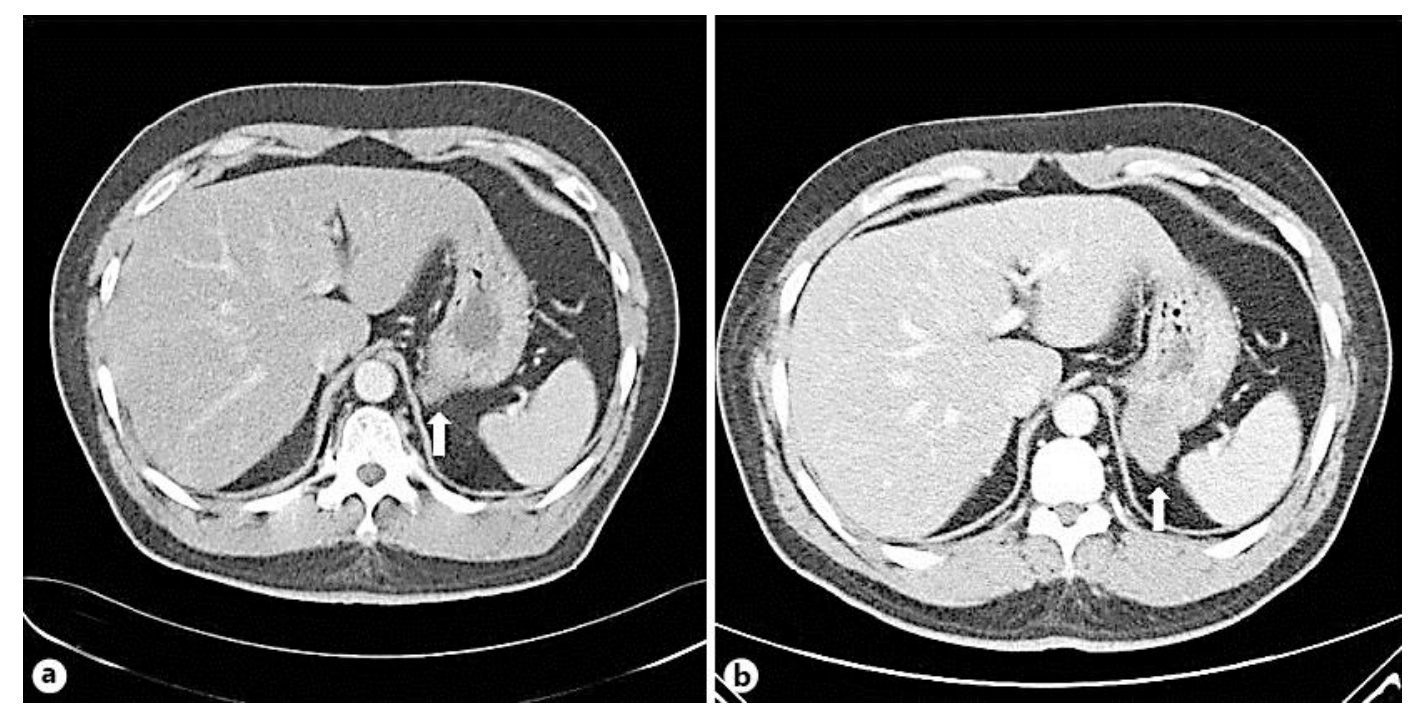

Fig. 2. Suspicious lesion in the left adrenal area. a In November 2011, computed tomography disclosed a small, ill-defined tumor $(1.8 \times 1.4 \mathrm{~cm})$ in the left adrenal area. $\mathbf{b}$ In May 2012, a remarkable enlargement of the previously suspected left adrenal tumor was noted $(3.3 \times 2.5 \mathrm{~cm})$.
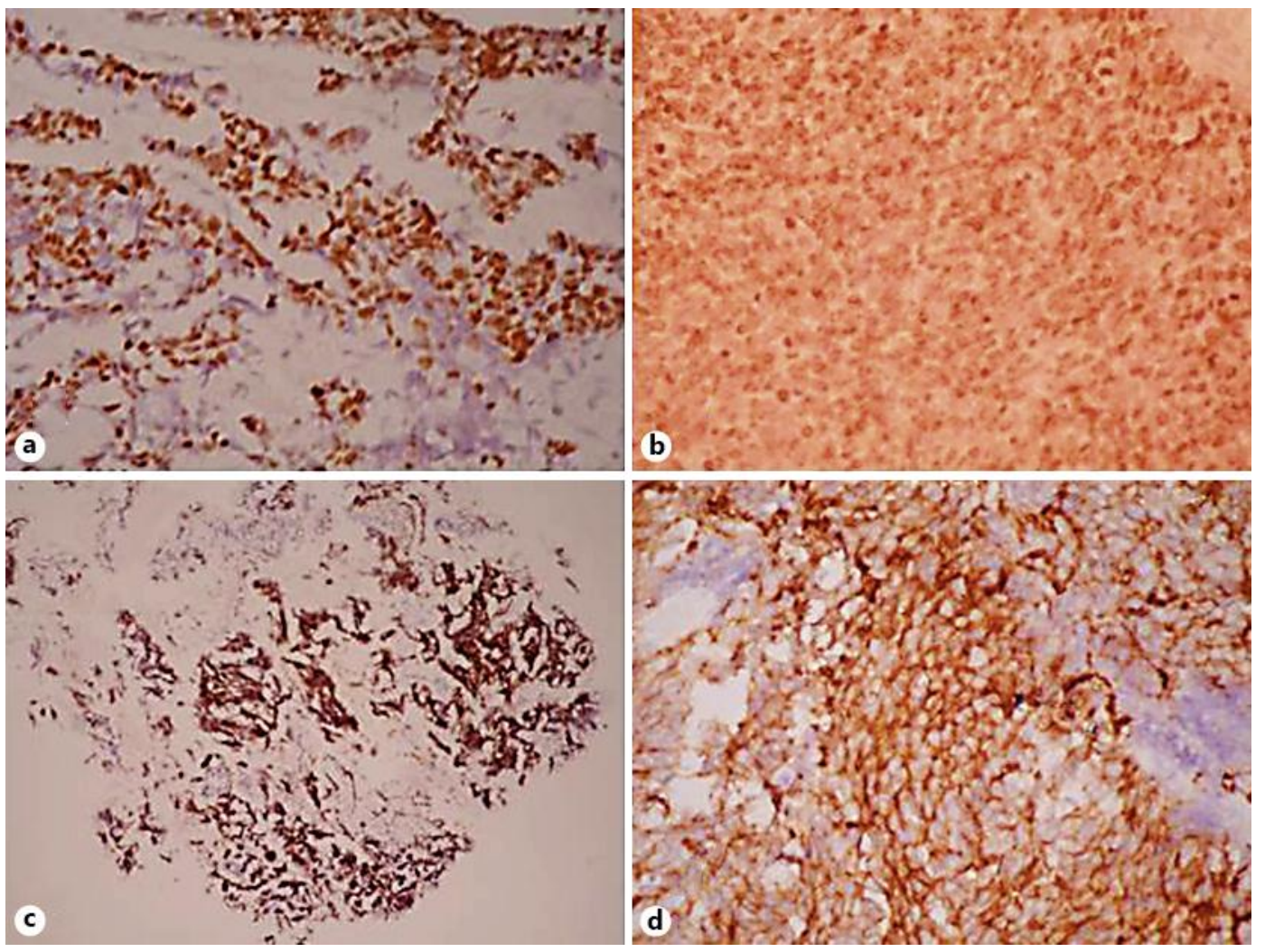

Fig. 3. Immunohistochemical stain was positive both for TTF-1 and CD-56. a Lung TTF-1 ( $\times 400)$. b Stomach TTF-1 (×400). c Lung CD-56 (×100). d Stomach CD-56 (×400). 